\title{
Aanvaarbaarheid van 'n nuwe model vir technikonopleiding in biblioteek- en inligtingkunde: 'n Delphi-studie
}

\author{
A.J van Vuren* \\ Gold Fields Library and Information Centre, Technikon SA, Privaatsak X90, Florida, 1710 Republiek van Suid-Afrika
}

Berendien L. Oosthuizen

Departement Inligtingstudies, Randse Afrikaanse Universiteit, Posbus 524, Auckland Park, 2006 Republiek van Suid-Afrika

Ontvang Maart 1996; aanvaar Maart 1997

\begin{abstract}
Acceptability of a new model for technikon training in library and information science: a Delphi study. In view of the changed political and social situation in South Africa which impacts directly on tertiary education, an investigation was conducted on the possibility of changing the qualification structure of the library and information science course at a technikon. This article reports on the testing of the level of acceptance in the information profession of a proposed new model for the qualification structure. The research was done by means of a Delphi study. The most important result was that the professional community supports a changed qualification structure for technikon training through distance education. Problems were pointed out that might arise from the implementation of such a changed qualification structure.
\end{abstract}

In die lig van veranderde politieke en sosiale omstandighede in Suid-Afrika wat 'n direkte invloed op tersiêre onderrig het, is navorsing gedoen oor moontlike veranderinge in die kwalifikasiestruktuur van biblioteek- en inligtingkunde by 'n technikon. In hierdie artikel word verslag gedoen oor die aanvaarbaarheid van 'n nuwe model vir die inligtingspraktyk. Die ondersoek is gedoen deur middel van 'n Delphi-studie. Die belangrikste bevinding van die studie was dat die beroepsgemeenskap die wenslikheid van 'n veranderde kwalifikasiestruktuur vir technikonopleiding deur medium van afstandsonderrig ondersteun. Probleme met betrekking tot die implementering van 'n veranderde kwalifikasiestruktuur is wel uitgewys.

*Outeur aan wie korrespondensie gerig moet word.

Daar word algemeen aanvaar dat die biblioteek- en inligtingkundige praktyk wat gerig is op die behoeftes van die gemeenskap beïnvloed word deur die veranderinge in daardie gemeenskap. Die faktore wat die grootste invloed op die gemeenskap uitoefen, is die veranderinge en ontwikkeling wat op politieke, sosiale, kulturele en tegnologiese gebied plaasvind. Dit is nie altyd moontlik om te voorspel in watter rigting en tot watter mate elk van hierdie gebiede op die lang termyn sal verander en ontwikkel nie. Die biblioteek- en inligtingsgemeenskap moet dus blywend ingestel wees op veranderings en tendense sodat aanpassings in doelstellings en dienslewering vroegtydig gemaak kan word om aan die toekomstige verwagtinge en eise te kan voldoen. Daar moet veral ook by die opleiding van biblioteek- en inligtingkundiges tred gehou word met die verskillende faktore wat 'n rol speel by die ontwikkeling van biblioteek- en inligtingsdienste, die behoeftes van die gebruikersgemeenskap en die gevolglike eise aan opgeleide professionele en paraprofessionele personeel. Daar moet insgelyks tred gehou word met ontwikkelinge op die gebied van die tersiêre onderwys as sodanig. Suid-Afrika het te staan gekom voor groot opvoedkundige en onderwyskundige uitdagings. Die konvensionele onderwysstelsel wat deur die loop van dekades hier gevestig en aanvaar is, is nie meer in staat om aan die opleidingsbehoeftes in die land te voldoen nie. Die klem is daarom besig om te verskuif vanaf konvensionele onderwys en opleiding na modelle soos lewenslange leer en bekwaamheidsgebaseerde onderwys. Die herbesinning oor kwalifikasiestrukture en die ontwikkeling van die Nasionale Kwalifikasieraamwerk (NKR), is 'n uitvloeisel hiervan.

Die oogmerk van die NKR is om die manier waarop daar oor onderwys en opleiding gedink word, te verander. Die deurslaggewende faktore by onderwys en opleiding behoort hiervolgens te wees dat:

- alle vorme van kennis waardevol is binne die nasionale ekonomiese en gemeenskapsontwikkeling; en

- alle leeraktiwiteit gerig behoort te wees op die uitbreiding van die leerder se bekwaamheid en nie net sy kennis nie (Human Sciences Research Council 1995:12).

Teen hierdie agtergrond is daar indringend navorsing gedoen oor die moontlike aanpassing van die kwalifikasiestruktuur vir technikonopleiding deur medium van afstandsonderrig sodat daar meerdere voorgraadse hiërargiese kwalifikasievlakke kan wees (Van Vuren 1995). 'n Model vir 'n aangepaste kwalifikasiestruktuur is ontwikkel wat in 'n vorige artikel in hierdie blad volledig bespreek is (Van Vuren \& Oosthuizen 1995:39-47). Die model stel drie volledig ineengeskakelde vlakke van voorgraadse opleiding vir technikonopleiding in Suid-Afrika voor, te wete:

- 'n Eerste vlak van opleiding bestaande uit 'n inleidende sertifikaat in biblioteek- en inligtingspraktyk.

- 'n Tweede vlak van opleiding bestaande uit 'n aantal gelykwaardige sertifikate wat fokus op spesifieke taakareas en vaardighede, byvoorbeeld 'n sertifikaat in ontsluiting, inligtingsherwinning, leendienste (dokumentlewering), ensovoorts. 'n Voorgeskrewe aantal van hierdie sertifikate, plus modules gerig op die verwerwing van 
toesighoudings- en bestuursvaardighede vir middelvlakbestuur, kan saam genoeg krediete verskaf vir die verwerwing van die nasionale diploma in biblioteek- en inligtingspraktyk.

- 'n Derde vlak van opleiding bestaande uit 'n technikongraad (B Bibl Tech).

Elkeen van hierdie vlakke kan 'n intree- en/of uittreevlak wees (kyk na Bylae 1).

\section{Doel van die artikel}

Die kwalifikasiestruktuur vir technikonopleiding in biblioteek- en inligtingkunde deur medium van afstandsonderrig, kan nie eensydig verander word nie. Dit is baie belangrik dat so ' $n$ verandering vir die biblioteek- en inligtingkundige beroepspraktyk aanvaarbaar moet wees. Postestrukture en vereistes vir indiensneming word immers deur die praktyk bepaal. Die praktyk se mening omtrent 'n veranderde kwalifikasiestruktuur is daarom in die studie bepaal. Die doel van hierdie artikel is om verslag te doen oor die vasstelling van die vlak van aanvaarbaarheid by die beroepsgemeenskap van 'n veranderde kwalifikasiestruktuur vir technikonopleiding in biblioteek- en inligtingkunde deur medium van afstandsonderrig (soos deur die model voorgestel). Die navorsing is deur middel van 'n Delphi-studie gedoen (Van Vuren 1995).

\section{Delphi-studie}

\section{Motivering vir die gebruik van die metode}

Beplanning en besluitneming is twee van die belangrikste funksies van bestuurders - ook van opleidings- en akademiese bestuurders. Die toekoms van opleiding op die gebied van biblioteek- en inligtingkunde berus in 'n groot mate op akademiese bestuurders wat moet besin oor en beplan vir verwagte toekomstige behoeftes en tendense. In die loop van hierdie proses moet hulle so raak as moontlik probeer voorspel wat die toekoms gaan vereis ten opsigte van die bevrediging van spesifieke opleidingsbehoeftes. Voorspelling as sodanig is geen maklike taak nie en lê iewers op die kontinuum tussen kennis en spekulasie. Kennis word ondersteun deur bewyse terwyl spekulasie geen bewysgronde het nie. Voorspelling (en opinie) word ondersteun deur 'n mate van kennis (Fischer 1978:64). Die aanname onderliggend aan voorspelling en die gepaardgaande beplanning is dat die toekoms nie voorbeskik is nie maar beheer kan word deur tydige besluite.

Rasionele besluitneming binne die navorsingsproses is een van die belangrikste take van 'n navorser (Mouton \& Marais 1989:33). Die keuse van 'n navorsingsmetode en die beplanning van die navorsingsproses is sekerlik die belangrikste besluite wat die navorser moet neem. Die aard van die probleem wat in hierdie navorsing ondersoek is, vereis 'n mate van voorspelling. Die toekomstige behoeftes van die biblioteek- en inligtingkundige praktyk moet geantisipeer word. Daar is dus 'n behoefte aan ontlokking van opinies oor die waarde of gewensdheid van moontlike toekomstige ontwikkelinge. Die Delphi-metode van ondersoek leen hom tot die ontlokking van opinies sowel as voorspelling.

Die metode behels die inwin en verfyning van die opinies van kundiges oor 'n sekere aspek van die huidige of toekomstige situasie. Daar word gepoog om konsensus van opinie oor die saak te verkry. So 'n konsensus van opinie kan dan as 'n voorspelling van toekomstige ontwikkeling beskou word. Martyn en Lancaster (1981:57) beskou 'n voorspelling as 'n raming of skatting van wat in die toekoms op 'n bepaalde gebied gaan gebeur, wat gebaseer is op die ingeligte menings van kundige individue. Aangesien niemand kennis oor die toekoms kan hê nie en daar verhoed moet word dat op spekulasie teruggeval word, word daar met die Delphimetode bewustelik gesoek na die ingeligte opinie van kundiges. Weingand (1989:39) wys daarop dat intuïsie 'n rol speel by die opinievorming en voorspelling juis omdat daar nie met absolute sekerheid oor die toekoms gepraat kan word nie. Die gebruik van die Delphi-metode kan die wetenskaplikheid en betroubaarheid van voorspellings verhoog en die mate waarin op intuïsie staat gemaak word, verminder. Kundiges wat steun op hul ingeligte intuitiewe kennis kan egter nie heeltemal uitgeskakel word nie. Die Delphi-metode staan in die lig hiervan bekend as 'n tegniek wat gebruik maak van die intuïtiewe kennis van kundiges.

\section{Beskrywing van die Delphi-metode}

Olaf Helmer (Busha \& Harter 1980:176), een van die ontwikkelaars van die metode, beskryf dit as

'... a carefully designed program of sequential individual interrogations (best conducted by questionnaires) interspersed with information and opinion feedback ...'

Die metode kan beskryf word as 'n konferensie oor die pos. Die basiese elemente daarvan is ' $n$ paneel van kundiges en ' $n$ vraelys wat in 'n aantal 'rondtes' aan die paneel gestuur word om hulle menings te bepaal oor wat op 'n bepaalde gebied gaan of moet gebeur. Die paneellede bly anoniem en is nie van mekaar se identiteit bewus nie.

Die vraelys word aan paneellede gestuur saam met 'n inligtingstuk wat agtergrondinligting verskaf oor die navorsing. Die inligtingstuk speel 'n belangrike rol in die ondersoek omdat dit paneellede help om 'n sinvolle bydrae te maak (Fischer 1978:68). Die vraelyste word na hul terugontvangs geanaliseer en die paneellede se reaksie word verwerk sodat dit as terugvoering aan al die ander paneellede gestuur kan word. Die siklus word dan herhaal deurdat die vraelys en die terugvoering aan paneellede gestuur word met die versoek om dit weer te voltooi met die inagneming van die res van die paneel se standpunte. Redes vir enige verskille met die res van die paneel moet verstrek word. Die siklus word herhaal totdat konsensus bereik is, of dit duidelik is dat konsensus nie bereik kan word nie.

Daar is in hierdie ondersoek van die klassieke Delphiontwerp afgewyk deurdat van twee panele gebruik gemaak is om die praktyk se menings oor die aanvaarbaarheid van 'n veranderde kwalifikasiestruktuur te bepaal. Die rede hiervoor 
sal duidelik word uit die beskrywing van die eienskappe van die twee panele.

\section{Paneel 1: eienskappe en terugvoering}

Die eerste paneel van kundiges is saamgestel uit persone uit hoofsaaklik 'n middelbestuursvlak wat gedurende 1993 as mentors opgetree het vir Technikon SA studente vir die Nasionale Diploma: Biblioteek- en Inligtingspraktyk. Daar is 'n volledige Delphi-studie van drie rondtes met behulp van hierdie paneel gedoen. Die keuse het op die mentors geval omdat geredeneer is dat hulle betrokkenheid by hul student hulle waarskynlik opnuut bewus gemaak het van die belang van opleiding en die probleme verbonde aan afstandsonderrig. Die mentors se praktykervaring het waarskynlik ook al vir hulle aangedui waar die leemtes in die opleiding van studente is.

Daar is aanvanklik 30 mentors geselekteer om aan die projek deel te neem. Van hierdie 30 persone het 18 die hele projek voltooi. Daar word in die literatuur verwys na die belangrikheid van die samestelling van die paneel en dat 'n swak paneel die resultate nadelig kan beïnvloed. Hoewel dit ' $n$ probleem is, is dit nie eie aan die Delphi-metode nie en geld dit vir enige groepaktiwiteit soos die samestelling van 'n komitee of 'n studiegroep. Daar is nogtans met die aanvanklike seleksie van deelnemers gepoog om gelyke verteenwoordiging aan al die verskillende tipes biblioteek- en inligtingsdienste te gee. Die navorser het egter nie beheer oor hoeveel en watter paneellede enduit by die projek betrokke sal bly nie. Paneellede is toe hulle genader is om op die paneel te dien, daarop gewys dat hulle bereid moet wees om aan al die rondtes deel te neem. Die samestelling van die finale paneel van 18 lede het soos volg daar uitgesien:

\section{Geslag \\ Manlik \\ Vroulik \\ 3 15}

\section{Kwalifikasies}

$\begin{array}{ccccc}\text { BA Bibl } & \text { B Bibl } & \text { Hons } & \text { M Bibl } & \text { HDB } \\ 4 & 2 & 5 & 4 & 3 \\ \text { Beroepservaring } & & & \\ 5-10 \mathrm{jr} & 11-15 \mathrm{jr} & 16-20 \mathrm{jr} & 21-25 \mathrm{jr} & 26-30 \mathrm{jr} \\ 1 & 7 & 4 & 3 & 3\end{array}$

Tipe biblioteek- en inligtingsdiens

$\begin{array}{cccc}\text { Openbaar } & \text { Akademies } & \text { Spesiaal } & \text { Nasionaal } \\ 9 & 4 & 4 & 1\end{array}$

Met die eerste oogopslag lyk dit asof die paneel 'n oorwig van openbare bibliotekarisse bevat. Die verhouding openbare biblioteek teenoor ander tipes biblioteke is egter gelyk, naamlik nege elk. 'n Oorwig van openbare bibliotekarisse sou die resultaat kon beinvloed omdat hierdie biblioteektipe betrokke is by die lewering van 'n wye spektrum van dienste aan 'n verskeidenheid van groepe binne die gemeenskappe wat hulle bedien en dus moontlik 'n groter behoefte het aan personeel wat op verskillende vlakke opgelei is.

\section{Paneel 2: eienskappe en terugvoering}

Die uitslag van die ondersoek is daarna aan 'n tweede paneel voorgelê om hulle reaksie op die eerste paneel se siening te toets. Die tweede paneel is saamgestel uit persone in senior bestuursposisies in van die land se grootste biblioteek- en inligtingsdienste. Die biblioteek- en inligtingkundige werksomgewing bestaan uit verskillende soorte biblioteek- en inligtingsdienste. Bibliotekarisse aan die hoof van die verskillende biblioteektipes, moet afgesien van die normale biblioteek- en inligtingkundige bestuursfunksies, ook vertroud wees met die werking en struktuur van die moederorganisasie waarvan hulle biblioteek- en inligtingsdiens deel uitmaak en op die hoogte wees met die beleid met betrekking tot indiensneming van personeel en die bepaling van postestrukture. Hulle oefen op hulle beurt ook 'n invloed uit op die vereistes wat aan personeel gestel word en die aantal en soort poste waarvoor voorsiening gemaak word. Dit was dus belangrik om te weet of biblioteekbestuurders se menings omtrent die wenslikheid en aanvaarbaarheid van 'n meer aanpasbare kwalifikasiestruktuur ooreenstem met dié van middelvlakbestuurders en gewone praktiserende bibliotekarisse.

Daar is aanvanklik 15 persone geselekteer om op die tweede paneel te dien, waarvan nege die vraelys voltooi het. Die eienskappe van die paneel kan soos volg opgesom word:

\begin{tabular}{|c|c|c|c|}
\hline \multicolumn{4}{|l|}{ Geslag } \\
\hline Manlik & \multicolumn{2}{|c|}{ Vroulik } & \\
\hline 7 & \multicolumn{2}{|c|}{2} & \\
\hline \multicolumn{4}{|c|}{ Kwalifikasies } \\
\hline HDB & Hons & M Bibl & D Phil \\
\hline 2 & 3 & 2 & 2 \\
\hline \multicolumn{4}{|c|}{ Beroepservaring } \\
\hline $11-15 \mathrm{jr}$ & $16-20 \mathrm{jr}$ & $21-25 \mathrm{jr}$ & $26-30 \mathrm{jr}$ \\
\hline 1 & 1 & 2 & 5 \\
\hline \multicolumn{4}{|c|}{ Tipe biblioteek- en inligtingsdiens } \\
\hline $\begin{array}{c}\text { Openbaar } \\
2\end{array}$ & $\begin{array}{c}\text { Akader } \\
4\end{array}$ & nies $\begin{array}{c}\text { Spes } \\
2\end{array}$ & $\begin{array}{c}\text { Nasionaal } \\
1\end{array}$ \\
\hline
\end{tabular}

Die twee panele vergelyk goed wat beroepservaring en kwalifikasies betref. Die groter aantal manlike respondente kan toegeskryf word aan die feit dat daar meer mans in senior bestuursposisies is as vroue. Die oorwig van die akademiese en ander biblioteke teenoor die openbare biblioteek is as gevolg van die feit dat nie al die paneellede die vraelys voltooi het nie. Dit kon wel, soos hierbo genoem, die resultaat van die navorsing beïnvloed het.

\section{Vraelys}

Daar kan op twee maniere te werk gegaan word om die vraelys vir 'n Delphi-studie saam te stel. Die navorser kan dit saamstel of die paneellede kan gevra word om vrae oor die onderwerp voor te stel. Indien die paneellede se insette gevra word, word dit as Rondte 0 beskou. Dit bly egter die verantwoordlikheid van die navorser om te sorg dat die vrae ondubbelsinnig en ewewigtig is. 'n Kombinasie van die twee metodes kan ook gebruik word deurdat die navorser 'n voorlopige vraelys opstel en dan voorstelle vanaf die paneel vra. 
Die paneellede se voorstelle met betrekking tot vrae word bestudeer en in die vraelys verwerk. Hierdie vraelys word dan aan paneellede gestuur as Rondte 1 van die ondersoek.

Daar is in hierdie ondersoek gebruik gemaak van die kombinasie van die twee metodes. ' $n$ Vraelys is opgestel wat gestruktureer is volgens die voorgestelde drie vlakke waaruit 'n veranderde kwalifikasiestruktuur moontlik kan bestaan. Die belangrikste aspekte wat gedek is, is die volgende:

- Die belangrikheid van verskillende intree/uittreevlakke.

- Die toelatingsvereistes vir die verskillende intree/uittreevlakke. In die lig van die groot behoefte aan opleiding by die agtergeblewe gedeelte van die Suid-Afrikaanse samelewing, was dit nodig om die praktyk se mening oor die aanvaarbaarheid van die toelating van kandidate sonder matriek tot biblioteek- en inligtingkundige studie, te bepaal.

- Die aanvaarbaarheid van sertifikate as beroepskwalifikasies en die aanvaarbaarheid van sertifikaathouers binne die beroepsgemeenskap.

- Die aanvaarbaarheid van sertifikate wat gebaseer is op verskillende taakareas.

- Die aanvaarbaarheid van 'n kombinasie van sertifikate as diploma.

- Die aanvaarbaarheid van die skepping van 'n oorgang vanaf paraprofessionele na professionele opleiding vir technikonstudente (kyk na Bylae 2).

\section{Bespreking van bevindinge}

Aanpasbaarheid van die kwalifikasiestruktuur en verskillende intree- en uittreevlakke

'n Stelsel van hiërargiese kwalifikasies wat voorsiening maak vir meer intree- en uittreevlakke sal vir die professie aanvaarbaar wees. Hierdie resultaat sluit aan by die siening van Horton (1993:235) en Nassimbeni, Stilwell en Walker (1993: 37) dat daar 'n leemte in die huidige kwalifikasiestruktuur vir opleiding in biblioteek- en inligtingkunde is aangesien daar nie voldoende voorsiening gemaak word vir uittreevlakke laer as diplomavlak nie. Dit veroorsaak dat daar nie in die opleidingsbehoeftes van spesifieke groepe binne die professie voorsien kan word nie en dat die mobiliteit van studente tussen die verskillende opleidingsinstellings belemmer word.

Die twee panele se reaksie met betrekking tot die wenslikheid van meerdere intree/uittreevlakke word in Figuur 1 gegee. Die skaal wat gebruik is, verteenwoordig 'n stygende lyn van belangrikheid of aanvaarding vanaf 1 tot 5 . Die figure wat in die resultate gebruik word, dui die gemiddelde mening (konsensus) van die lede van die panele aan. Die standaardafwyking van \pm een $(x \pm S A)$ dui die variasie van mening tussen die paneellede aan.

Albei panele is van mening dat ' $n$ meer aanpasbare kwalifikasiestruktuur belangrik en aanvaarbaar is. Paneel 1 is meer positief as Paneel 2, met 'n gemiddelde waarde van 4.4 teenoor Paneel 2 se gemiddelde waarde van 4. Paneel 1 is ook meer eenstemmig as Paneel 2, soos deur die kleiner standaardafwyking aangedui. In terme van die skaal in die geheel

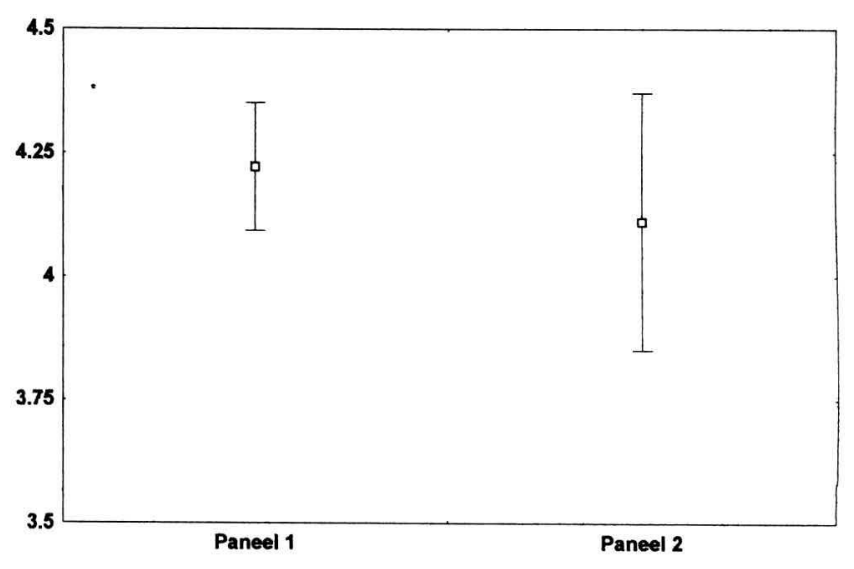

Figuur 1 Aanvaarbaarheid van verskillende intree- en uittreevlakke

is die gemiddelde waardes wat die panele toegeken het, hoog en dui dit daarop dat die praktyk waarskynlik veranderinge in hierdie verband sal aanvaar. Die opmerkings van paneellede het getoon dat hulle ' $n$ veranderde, meer aanpasbare kwalifikasiestruktuur sien as 'n manier waarop die tekort aan opgeleide personeel in die agtergeblewe gemeenskappe aangevul kan word. Die opmerking is ook gemaak dat dit sal help om regstellende aksie te ondersteun. Verskeie paneellede het reeds in hierdie stadium daarop klem gelê dat aanpasbaarheid nie ten koste van standaarde bereik mag word nie en dat kwalifikasies wat so ontstaan nie afgewater mag wees nie. Paneellede het ook gewys op die voordele wat 'n meer aanpasbare kwalifikasiestruktuur kan hê op die gebied van voortgesette opleiding en heropleiding van reeds gekwalifiseerde personeel omdat personeel wat voel dat hulle sekere vaardighede wil opskerp of op die hoogte wil kom van nuwe ontwikkelinge binne die professie, sou kon inskryf vir van die sertifikaatkursusse.

\section{Aanvaarbaarheid van sertifikate as kwalifikasies}

'n Sertifikaatkwalifikasie vereis 'n leergang wat die ekwivalent van een jaar voltydse tersiêre studie in beslag neem. 'n Hoër sertifikaat vereis 'n leergang wat die ekwivalent van twee jaar voltydse tersiêre studie in beslag neem en 'n diploma vereis 'n leergang wat die ekwiwalent van drie jaar voltydse tersiêre studie in beslag neem. Die twee panele se sienings met betrekking tot die aanvaarbaarheid van sertifikate word in Figuur 2 aangedui.

Albei panele was dus van mening dat sertifikate as kwalifikasies aanvaarbaar sal wees. Paneel 1 is in die geheel meer positief, met 'n gemiddelde waarde van 3.7 teenoor die 3 van Paneel 2, maar is minder eenstemmig as Paneel 2.

Daar was dus geen beginselprobleme met betrekking tot die aanvaarbaarheid van sertifikaatkwalifikasies nie. Daar is wel voorsien dat die implementering van hierdie tipe kwalifikasies sekere probleme teweeg kan bring, veral met betrekking tot die akkommodering van sertifikaathouers binne bestaande postestrukture en die betiteling van personeel wat oor slegs ' $n$ enkele sertifikaat of sertifikate beskik. Die kwessie van die aanpassing van postestrukture beklemtoon weereens die belangrikheid van samewerking tussen die opleiers 


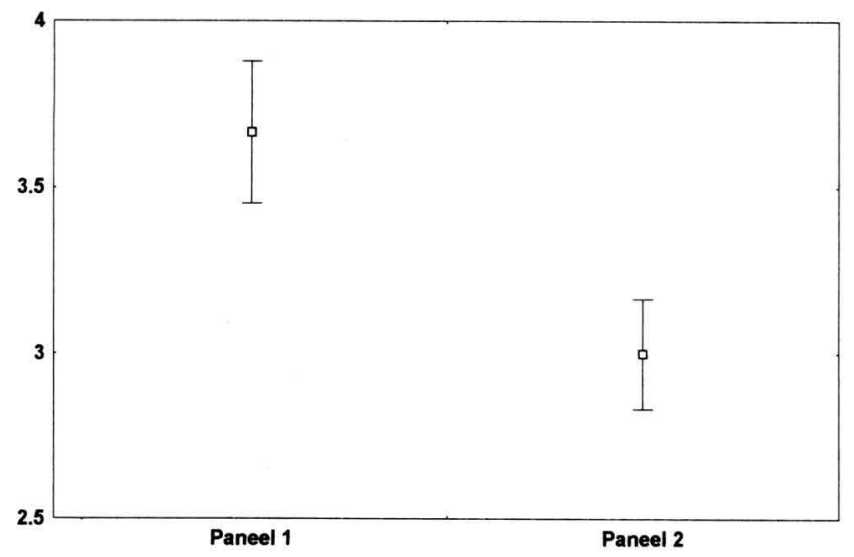

Figuur 2 Aanvaarbaarheid van sertifikate as kwalifikasies

en die praktyk. Volgens Usmani (1987:iiv) dien die verwerwing van 'n sertifikaat en die erkenning daarvan in die werkplek, dikwels as aansporing tot verdere studie. Die teenoorgestelde kan egter ook gebeur. Indien die praktyk nie voorsiening gaan maak vir postestrukture waarbinne sertifikaathouers erkenning en aanmoediging kan ontvang nie, sal pogings van opleidingsinstansies om in die leemtes met betrekking tot verskillende vlakke van paraprofessionele opleiding te voorsien, nie suksesvol wees nie. Die formele erkenning van sertifikate deur middel van die aanpassing van postestrukture moet voorafgegaan word deur vertroue in die standaard van die kwalifikasie en kennis oor die doel van sertifikate. Dit sal verhoed dat daar enersyds te veel van sertifikaathouers verwag word, en andersyds nie genoeg ruimte binne die werkplek aan hulle gegun word om te bewys dat hulle belangrike kennis en vaardighede verwerf het nie.

Dit is moeiliker om te bepaal waar die verantwoordelikheid vir die betiteling van die houers van sertifikaatkwalifikasies lê, waarskynlik by die professionele liggaam. Dit is 'n saak wat uiteraard eers aandag kan kry as/wanneer hierdie tipe kwalifikasie beskikbaar word.

\section{Groter beklemtoning van bekwaamheidsgebaseerde opleiding}

Soos reeds in die inleiding tot hierdie artikel aangedui, beklemtoon die NKR bekwaamheidsgebaseerde onderwys en opleiding. Die term bekwaamheidsgebaseerde onderwys verwys in breë terme na dit wat benodig word om effektief binne ' $n$ bepaalde beroep of pos te funksioneer (Jessup 1989:75), met besondere klem op die vermoë om te doen (Wolf 1989: 40).

Daar word in die voorgestelde veranderde kwalifikasiestruktuur aangesluit by 'n sentrale onderrigpraktyk van bekwaamheidsgebaseerde onderwys, naamlik die verdeling van die leerinhoude wat spesifieke vaardighede ondersteun in verskillende, makliker hanteerbare studie-eenhede (Tuxworth 1989:13). 'n Struktuur wat by hierdie beginsel aansluit, kan dit vir studente moontlik maak om hulle agtereenvolgens vir verskillende taakareas binne die biblioteek- en inligtingkundige praktyk te bekwaam en 'n kwalifikasiebewys daarvoor te verwerf. Die term taakarea word gebruik om aan te dui dat daar nie te eng op handelingsvaardighede (ten koste van intellektuele vaardighede) gefokus sal word nie. Die student moet gelei word tot begrip vir die konteks waarbinne die taak verrig word (Van Vuren \& Oosthuizen 1996:43).

Beide panele het die gedagte van sertifikate gebaseer op verskillende taakareas redelik aanvaarbaar gevind. Die gemiddelde waardes wat deur Paneel 1 toegeken is, lê tussen 3.5 en 4 en die van Paneel 2 tussen 3 en 3.5 .

\section{Vryheid van keuse en diversifikasie van opleiding}

Die voorsiening wat in die mòdel vir ' $n$ veranderde kwalifikasiestruktuur gemaak is vir gelykwaardige sertifikate wat op spesifieke taakareas fokus (Van Vuren \& Oosthuizen 1996: 43), impliseer 'n groter mate van vryheid van keuse vir studente met betrekking tot die leerinhoude wat van toepassing is op die biblioteek- en inligtingsdiens waarin hulle werk, of belangstel om in te werk. Volgens Harvard-Wiliams (1987:99) is dit 'n sterk motiveringselement vir studente indien hulle seggenskap het oor watter vakke/kursusse hulle op wil konsentreer. Beide panele het die moontlikheid van groter vryheid van keuse met betrekking tot leerinhoude as belangrik beskou, (Paneel $1=3.7$ en Paneel $2=3.4$ ) maar was bewus daarvan dat een van die gevolge van die onderhandelbaarheid van leerinhoude en die vryheid van keuse wat dit meebring, groter diversifikasie van die opleiding is. Met diversifikasie word bedoel dat 'n student kan kies (binne perke) watter aspekte van die biblioteek- en inligtingkunde hy eerste wil bestudeer, omdat dit vir hom sekere voordele inhou. Die vrees is wel uitgespreek dat dit te veel en te vroeë spesialisasie aan die hand kan werk. Daar kan egter beswaarlik van spesialisasie gepraat word op die vlak van opleiding wat hier ter sprake is. Spesialisasie word gewoonlik gedefinieer as 'n area of terrein waarop iemand hom toelê of besondere bekwaamheid verwerf het. Die gedagte hier is slegs dat die verskillende taakareas afsonderlik bestudeer word en dat 'n volledige kwalifikasie eers behaal word wanneer al die taakareas bestudeer is. Die vrees is egter uitgespreek dat so 'n stelsel nadelige gevolge kan hê indien 'n student ophou studeer voordat al die taakareas bestudeer is.

Hierdie resultaat is bemoedigend omdat dit ' $n$ aanduiding is dat vryheid van keuse nie gesien word as 'n poging van die opleidingsinstansie om sy verantwoordelikheid na die student te verplaas nie, maar - vir wat dit is - die daarstelling van 'n struktuur wat bydra tot die bevrediging van die opleidingsbehoeftes van die individuele student wat reeds werksaam is binne die biblioteek- en inligtingkundige praktyk. Die onderhandelbaarheid van die leerinhoud met die leerder (binne 'n bepaalde raamwerk) is een van die beginsels van ooponderrig en is van besondere belang vir volwasse studente wat reeds in die praktyk staan en deur medium van afstandsonderrig studeer. Dit is ' $n$ beginsel wat maklik toegepas kan word by afstandsonderrig omdat afstandsonderrig in wese individuele onderrig is. 


\section{Aanvaarbaarheid van 'n kombinasie van sertifikate as diploma}

Beide panele het die moontlikheid van 'n kombinasie van sertifikate as diploma, as aanvaarbaar beskou. Paneel 2 het weereens minder positief gereageer as Paneel 1, met 'n gemiddelde waarde van 3.3 teenoor 3.8. Dit het ook hier uit opmerkings van paneellede geblyk dat daar nie in beginsel beswaar is teenoor so 'n stelsel nie, maar dat bepaalde probleme met die implementering daarvan voorsien word. Die mening van die panele word in die volgende opmerking van een van die paneellede opgesom: 'In die geval van 'n kombinasie wat aan die nodige standaarde voldoen en die breë spektrum van benodigde vaardighede dek, is dit baie aanvaarbaar'. Die mening van die panele word in Figuur 3 voorgestel.

Ten opsigte van so 'n kombinasie moet in gedagte gehou word dat daar 'n hegte band tussen die kwalifikasiestruktuur en die inhoud van die kurrikulum is. Die verskeidenheid en leerinhoude van beskikbare sertifikate, die spesifieke kombinasie van sertifikate, die mate van vryheid van keuse ten opsigte van die kombinasie van sertifikate en die moontlike toevoeging van verpligte sertifikate, is alles faktore wat ' $\mathrm{n}$ rol behoort te speel by die ontwikkeling van die kwalifikasiestruktuur vir so 'n diploma.

\section{Oorgang vanaf paraprofessionele na professionele kwalifikasies}

Beide panele het gevoel dat dit baie belangrik is dat die gaping tussen paraprofessionele en professionele opleiding oorbrug moet word soos bewys is deur die feit dat 'n gemiddelde waarde van 4.3 deur beide die panele aan die vraag toegeken is. Paneel 2 was minder eenstemmig as Paneel 1 (kyk na Figuur 4).

Die panele se positiewe reaksie op die vraag oor die oorgang vanaf paraprofessionele na professionele opleiding is ' $n$ baie belangrike resultaat van hierdie navorsing. Die bestaan van verskillende vlakke van opleiding het net betekenis indien daar voorsiening gemaak word (en aanvaarding is) vir ' $n$ redelike en akademies aanvaarbare progressie vanaf een vlak na die volgende. Indien die moontlikheid van progressie van-

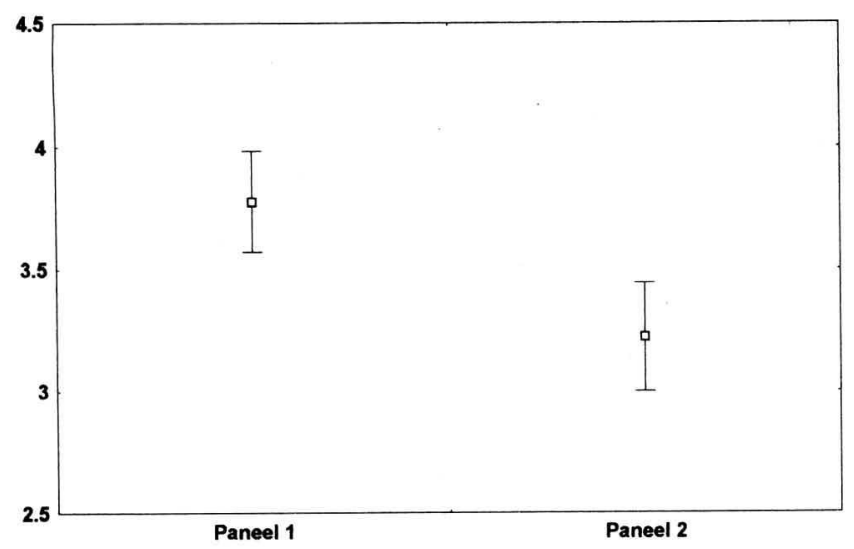

Figuur 3 Aanvaarbaarheid van 'n kombinasie van sertifikate as diploma

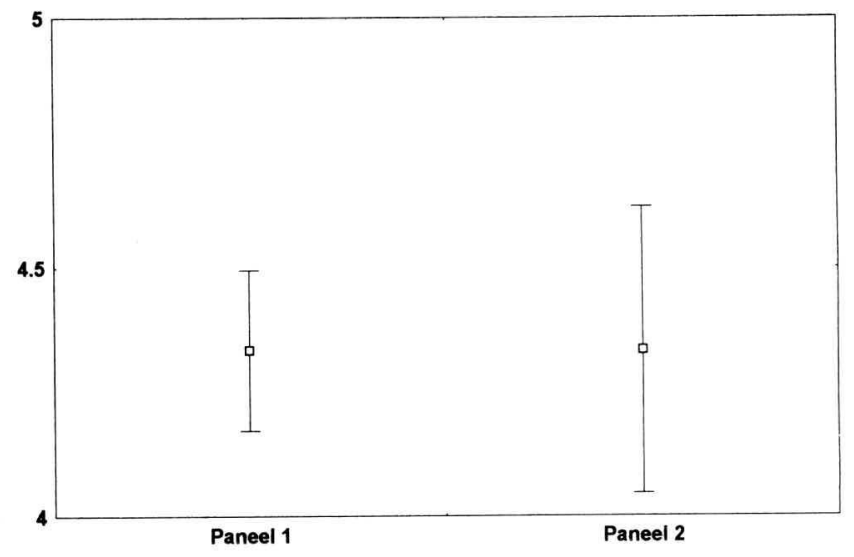

Figuur 4 Toegang tot graadkursus

af paraprofessioneel na professioneel nie bestaan nie, kan dit verdeeldheid skep en aanleiding gee tot beskuldigings van elitisme en oorbeklemtoning van professionaliteit.

\section{Toelatingsvereistes}

Dit het geblyk uit die resultate dat die praktyk moeilik toelatingsvereistes laer as matriek sal aanvaar selfs vir die eerste vlak van paraprofessionele opleiding. Die praktyk was bewus van die volgende:

- Die wisselvallige standaard van matriek in Suid-Afrika.

- Die behoefte van individue uit agtergeblewe gemeenskappe aan opleiding.

- Die feit dat verskillende vlakke van paraprofessionele personeel wenslik is.

- Die waarde van praktykervaring en die erkenning van reeds verworwe kennis.

Die gevoel was baie sterk dat die standaarde van die professie gehandhaaf en beskerm moet word en dat daar nie 'n verlaging in toelatingsvereistes moet wees ter wille van die opleiding van agtergeblewenes of die daarstelling van verskillende vlakke van paraprofessionele opleiding nie. Die toelatingvereistes vir die eerste en die opeenvolgende vlakke van paraprofessionele opleiding moet hiervolgens dus matriek wees omdat daar gevoel was dat matriek tog 'n sekere aansien in die gemeenskap het en 'n minimum standaard stel. Alhoewel die panele kan insien dat werkervaring ' $n$ kwalifiserende faktor by toelatingsvereistes kan wees, was daar tog voorbehoude oor die toelating van kandidate sonder matriek tot die eerste vlak van biblioteek- en inligtingkundige studie Daar is onder andere geargumenteer dat:

- Daar nie 'n gebrek aan kandidate met matriek is, wat in biblioteek- en inligtingkunde belangstel nie.

- Die agterstand wat kandidate sonder matriek het, gedurende die eerste vlak van opleiding aandag sal moet kry en dat die opleidingstaak hierdeur bemoeilik sal word.

- Die aanvaarding van kandidate sonder matriek die beeld van biblioteek- en inligtingswerkers (wat reeds nie baie positief is nie) skade kan berokken.

Die aandrang op matriek as toelatingsvereiste het egter implikasies vir 'n stelsel van nasionale beroepskwalifikasies en 'n nasionale kwalifikasieraamwerk. Die gedagte met 
hierdie tipe kwalifikasies is juis om weg te beweeg van die tradisionele beoordeling van bekwaamheid en potensiaal om 'n bepaalde kursus suksesvol te deurloop of 'n bepaalde beroep te kan hanteer. Die beroepsgemeenskap sal daaroor moet besin of die verwerwing van 'n sekere vlak van beroepskwalifikasie kan dien as 'n plaasvervanger vir matriek en dus aan die houers van hierdie kwalifikasies toelating kan gee tot formele studie in biblioteek- en inligtingkunde aan 'n technikon.

Die praktyk om kandidate sonder matriek tot paraprofessionele studie in biblioteek- en inligtingkunde toe te laat, bestaan in 'n aantal Afrika- en ander ontwikkelende lande. Die belangrikste voorbeelde is Botswana en Papua New Guinea. Kandidate wat die eerstevlak kwalifikasie (gewoonlik 'n sertifikaat) behaal, kom dan in aanmerking vir toelating tot verdere studie. Die vereiste word egter dikwels gestel dat so 'n kandidaat eers een of meer jare beroepservaring moet opdoen voordat met meer gevorderde studie voortgegaan kan word (Van Vuren 1995:87). Ainscough (1993:30) wys daarop dat die sertifikaat wat in die Seychelles verwerf word deur verskeie universiteite as toelating tot hulle kursusse aanvaar word:

'As the students are all mature the normal requirements for basic academic qualifications ( $\mathrm{O}$ or $\mathrm{A}$ levels) were, in the main regarded as superseded by experience and the certificate'.

Die toelatingsvereiste tot die sertifikaat van die Seychelles is bloot bewys van geletterdheid en een-jaar ervaring in 'n biblioteek- en inligtingsdiens.

\section{Gevolgtrekking}

Die resultate van die navorsing, in die geheel gesien, het aangetoon dat daar nie 'n weerstand teen verandering by die praktyk is nie. Daar is egter ook nie 'n gevoel vir verandering ter wille van verandering nie. Alhoewel daar dus aangedui is dat ' $n$ verandering in die kwalifikasiestruktuur vir opleiding in biblioteek- en inligtingkunde aanvaarbaar sal wees (en selfs noodsaaklik is), was die eis dat enige verandering sinvol en verantwoordbaar moet wees en moet bydra tot die ontwikkeling van die potensiaal van biblioteek- en inligtingkundiges. Paneel 2 het deurgaans, hoewel steeds positief, 'n effens laer vlak van aanvaarbaarheid as paneel 1 getoon. Die waarskynlike rede hiervoor is dat hulle vertroud is met bestaande bestuursmodelle in biblioteke en vanuit hierdie perspektief die implikasie van kwalifikasieveranderings beoordeel. Op grond van die resultate van dié Delphi-studie, wat die eienskap het dat dit voorspelling ondersteun, kan die volgende gevolgtrekking gemaak word:

Indien die kwalifikasiestruktuur vir opleiding in biblioteek- en inligtingkunde deur medium van afstandsonderrig verander sou word volgens die tentatiewe model wat in hierdie studie gebruik is, sou dit deur die panele uit die biblioteek- en inligtingkundige praktyk aanvaar word.

\section{Slot}

Die voorgestelde veranderde kwalifikasiestruktuur vir technikonopleiding in biblioteek- en inligtingkunde deur medium van afstandsonderrig kan in sekere opsigte as kompleks en moeilik uitvoerbaar beskou word. Biblioteek- en inligtingkunde as wetenskap en die biblioteek- en inligtingkundige praktyk met sy verskeidenheid van spesialisasierigtings en biblioteektipes is egter 'n komplekse studie en werksterrein. Die konvensionele opleidingstruktuur wat tot dusver gevolg is, is al dikwels as ontoereikend uitgewys. Harvard-Williams (1994:16+24-25) gebruik die konsep toepaslike opleiding (appropriate education) in navolging van die konsep van toepaslike tegnologie, om die noodsaak van aanpasbare biblioteek- en inligtingkundige opleiding in ontwikkelende lande toe te lig. Toepaslik beteken in hierdie konteks die inagneming van alle plaaslike omstandighede - die waardes, kultuur, ekonomie en hulpbronne binne 'n gegewe samelewing. Hierdie konsep geld egter nie net vir ontwikkelende lande nie, dit kan van toepassing gemaak word op alle biblioteek- en inligtingkundige opleiding. Daar moet met nuwe oë gekyk word na die totale biblioteek- en inligtingkundige werksomgewing en die opleiding wat daarvoor benodig word:

'Appropriate education is thus not simpler education, it is more complex, not least because the field of provision needs to be so much wider. Its content needs to be considered in the light of the needs of different levels and different activities (or lack of them): illiteracy, reading, education, administration and management, business and commerce, science and technology, recreation' (Harvard-Williams 1994: 24).

\section{Summary}

As part of a formal research project on the qualification structures in library and information science education a Delphi study was conducted to ascertain the level of acceptance amongst practitioners of possible change. This article reports specifically on the application of the Delphi method of investigation to establish whether a changed qualification framework for technikon training in library and information science through the medium of distance education would be accepted by the profession. The Delphi method as a research tool is discussed. The main elements of a Delphi study are: a panel of knowledgable individuals and a questionnaire, whereby informed opinions of the panel members are gained. To be able to reach consensus of opinion the questionnaires are distributed to the panel members in different rounds; each round containing the remarks of all the other members to be commented upon until consensus is reached. In this study two panels of specialists were used to represent 
- firstly, professional librarians involved in the training of library students by assuming the role of mentors (mainly middle management level); and

- secondly, senior managers of library and information services.

In general the results of the study indicated that practising librarians on both levels would not resist a changed qualification structure but that they do not want change for the sake of change - they expected any changes to contribute to the development of the potential of library and information science students. They were aware of the deficiencies of the current education and training structure and will accept change if it does not compromise standards. Although the two panels did not differ significantly in their views of the issues raised by the study, the second panel (the managers) were consistently more conservative and cautious. More specific results were the following:

- The panels will accept a hierarchical qualification structure that makes provision for more levels of education and training and for a variety of entrance and exit points. Such a structure could also facilitate continuous education and lifelong learning.

- Certificate-level qualifications will be acceptable but practitioners were concerned about accommodating these qualifications within existing job structures and about the entitling of certificate holders.

- The panels acknowledged that there is a need to look at the possibilities of competency-based education and training in library and information science, particularly since the idea of national-vocational qualifications, similar to those in Britain, is receiving serious consideration in South Africa.

- The panels agreed that allowing students more freedom of choice with regard to the specific themes within library and information science they want to pursue, will enable mature, distance education students to undertake studies which will be appropriate to their careers.

- Both panels felt strongly that it should be possible for students to progress from paraprofessional to professional education and training.

- The panels were reluctant to accept a change in the entrance requirements for study in library and information science.

\section{Verwysings}

Ainscough, P.J. 1993. A library and information certificate in the Seychelles. Library review, 42(4):27-38.

Busha, C.H. \& Harter, S.P. 1980. Research methods in librarianship: techniques and interpretations. New York: Academic Press.

Fischer, R.G. 1978. The Delphi method: a description, review and criticism. Journal of academic librarianship, 4(2):64-70.

Harvard-Williams, P. 1987. Looking towards the future: an overview. Education for information, 5(1/2):91-104.

Harvard-Williams, P. 1994. Appropriate education for library and information science. Libri, 44(1):14-27.

Horton, W. 1993. The structure of library education in South Africa. Journal of education for library and information science, 32(3):253-254.

Human Sciences Research Council. 1995. Ways of seeing the national qualifications framework. Pretoria: HSRC.

Jessup, G. 1989. The emerging model of vocational education and training, in Competency based education and training, ed. J. Burke. London: Falmer Press.

Martyn, J. \& Lancaster, W.F. 1981. Investigative methods in library and information science: an introduction. Arlington, Virginia: Information Resources Press.

Mouton, J. \& Marais, H.C. 1989. Metodologie van die geesteswetenskappe. Pretoria: RGN.

Nassimbeni, M., Stilwell, C. \& Walker, C. 1993. Education and training for library and information work: an analysis of the current South African situation with a view to the way forward. Innovation, 6:30-44.

Tuxworth, E. 1989. Competence-based education and training: background and origins, in Competency based education and training, ed. J. Burke.London: Falmer Press: 9-22.

Usmani, M.A. 1987. Certificate courses in library science: their contribution and recognition. Pakistan library bulletin, 18(23):iv.

Van Vuren, A.J. 1995. Kwalifikasiestruktuur vir technikonopleiding in biblioteek- en inligtingkunde deur middel van afstandsonderrig. D Litt et Phil-proefskrif, Randse Afrikaanse Universiteit, Johannesburg.

Van Vuren, A.J. \& Oosthuizen, B.L. 1996. Veranderde kwalifikasiestruktuur vir technikonopleiding in biblioteek- en inligtingkunde deur medium van afstandsonderrig: 'n model. Suid-Afrikaanse tydskrif vir biblioteek- en inligtingkunde, 64(4):39-47.

Visser, M.S.P. 1988. Tendense in die Suid-Afrikaanse biblioteek- en inligtingkundige situasie op mesovlak. Suid-Afrikaanse tydskrif vir biblioteek- en inligtingkunde, 56(1)27-37.

Weingand, D. 1989. Wisconsin continuing education profile: a Delphi projection of needs, 1986. Journal of education for library and information science, 30(1):39-51.

Wolf, A. 1989. Can competence and knowledge mix? In Competency based education and training, ed. J. Burke. London: Falmer Press: 3848. 
Bylae 1 Voorgestelde veranderende kwalifikasiestruktuur

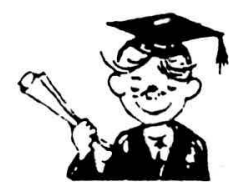

Uittreevlak

$=$

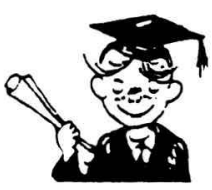

Technikongraad

$=$

Uittreevlak of toelating tot $=$

Bykomende modules gerig op topbestuurfunksies en diepere teoretiese onderbou

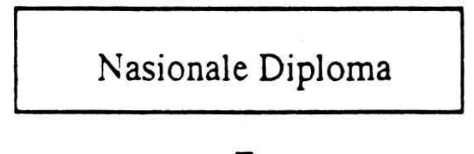

$=$

Bykomende modules gerig op middelbestuur m.b.t.

inligting en tegnologie

en teoretiese onderbou

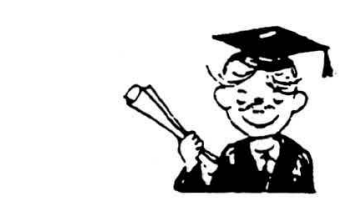

$+$

Uittreevlak of toelating tot $=$

Sertifikaat in spesifieke vaardigheid / kennisterrein, bv. katalogisering

$=$

Een of meer kursusse per jaar

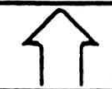

Keuse van modules gerig op verwerwing van basiese kennis en vaardighede,bv. katalogisering, inligtingherwinning, leendienste

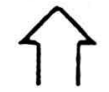

Vasgestelde aantal modules / jaarkursusse
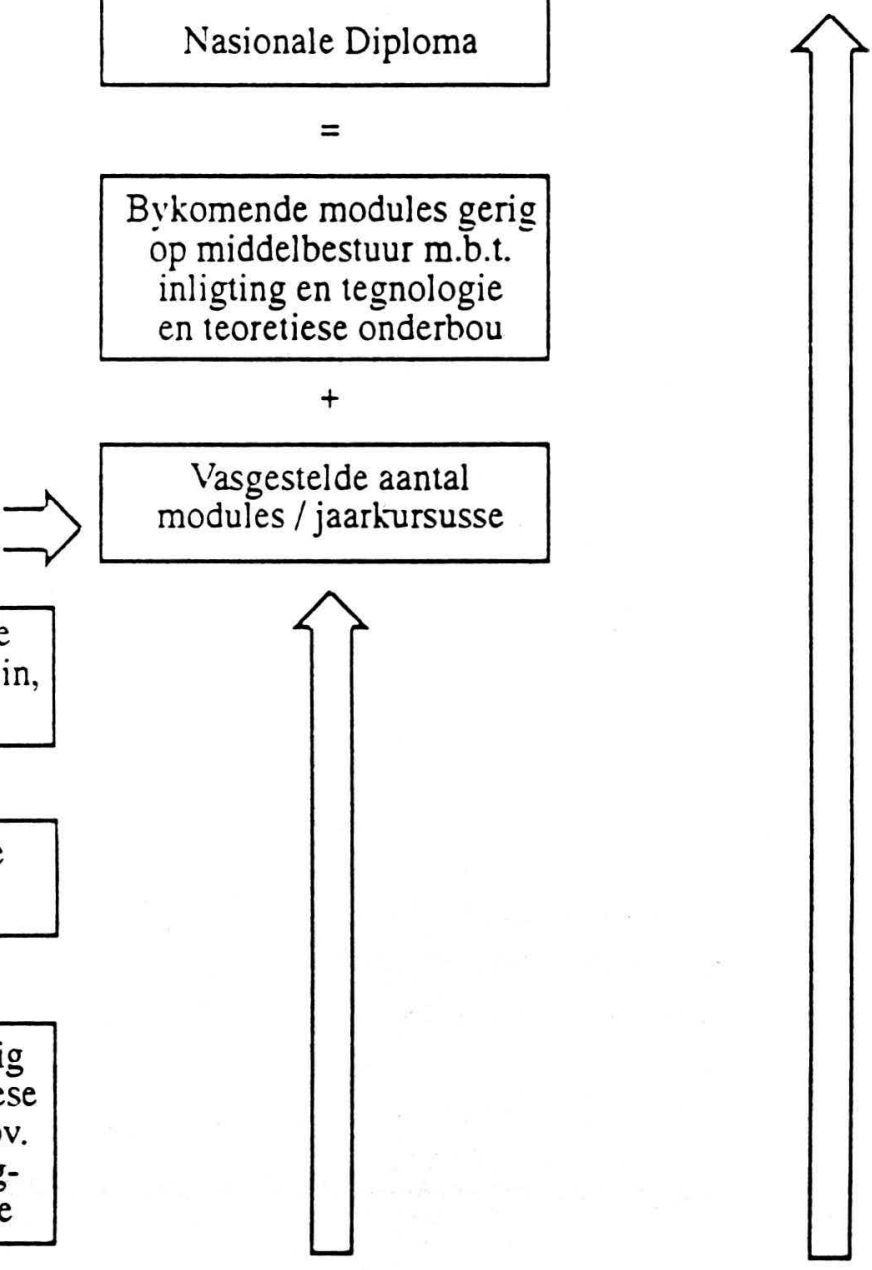

Eerste intree-/uittreevlak

St. 8, 9 + toelatingseksamens? Matriek / een of meer sertifikate? Matriek / Nasionale Diploma?

\section{Voorgestelde veranderde kw'alifikasiestruktuur}


Bylae 2 Vraelys

NAAM (opsioneel)

\section{AFDELING A: BIOGRAFIESE INLIGTING}
A. 1 Geslag:
M V

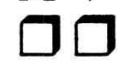

A.2 Soort biblioteek waar werksaam:
a) Akademiese biblioteek
b) Openbare biblioteek
c) Spesiale biblioteek
d) Ander (spesifiseer asseblief)

A.3 Posbenaming?

A.4 Hoogste kwalifikasie verwerf?

A.5 Aantal jare beroepservaring?

\section{AFDELING B}

Beoordelingskaal:

1 = nie van belang nie / nie aanvaarbaar nie

$2=$ van minder belang / minder aanvaarbaar

$3=$ taamlik belangrik / taamlik aanvaarbaar

$4=$ belangrik / aanvaarbaar

5 = uiters belangrik / totaal aanvaarbaar

Dui u keuse met ' $\mathrm{n}$ X in die toepaslike blokkie aan.

B.1 Hoe belangrik is ' $n$ meer aanpasbare kwalifikasiestruktuur volgens u mening?

$\begin{array}{lllll}1 & 2 & 3 & 4 & 5\end{array}$

$\square 00$

\section{Kommentaar}


B.2 In watter opsig moet die kwalifikasiestruktuur meer aanpasbaar wees?

a) Toelatingsvereistes?

b) Verskeidenheid van gelykwaardige kwalifikasies (bv. diplomas vir verskillende soorte biblioteke)

c) Verskeidenheid van hiërargiese kwalifikasies (sertifikate, diplomas, grade)

\section{Kommentaar}

B.3 Hoe belangrik dink $\mathrm{u}$ is dit dat daar verskillende intree- en uittreevlakke in die kwalifikasiestruktuur moet wees?

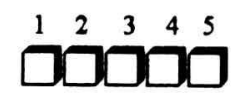

\section{Kommentaar}

B.4 Hoe aanvaarbaar sal elk van die volgende toelatingsvereistes volgens $u$ mening wees vir die eerste intree-/uittreevlak?

a) St. 9 plus twee jaar ondervinding in ' $n$ biblioteek- en inligtingsdiens.

b) Ouderdom 23 jaar en ouer en die slaag van ' $n$ toelatingseksamen

c) Minimum van twee jaar ondervinding in ' $n$ biblioteek/inligtingsdiens en slaag van 'n toelatingseksamen.

\section{Kommentaar}

B.5 Tot hoe ' $n$ mate dink u sal laer toelatingsvereistes as matriek (senior sertifikaat), die kwaliteit van biblioteek- en inligtingsdienste

a) Nadelig beïnvloed?

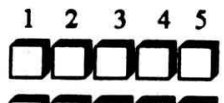

b) Voordelig beïnvloed? वण00

Skaal: 1 = glad nie; 2 = baie min; 3 = tot ' $n$ redelike mate; 4 = tot ' $n$ groot mate; 5 = ingrypend

B.6 Tot watter mate sal 'n sertifikaat deur die beroepsgemeenskap aanvaar word as kwalifikasie?

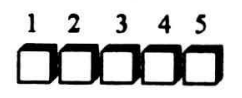

\section{Kommentaar}

B.7 Hoe aanvaarbaar sal sertifikate wees wat op die volgende gebaseer is:

1 Spesifieke take soos
a) Ontsluiting 
b) Inligtingsherwinning

ㅁㅁㅁ

c) Bedryf van leendienste

ㅁㅁㅁ

d) Hantering van inligtingstegnologie

पㅁㅁ

e) Gemeenskapsinligtingsdienste

00000

f) Aanskaf (aankoopbestuur en keuring)

वप्वण

g) Tydskrifte

h) Multimedia

00000

i) Biblioteekbevordering

वप्वण

j) Leserleiding

00000

0000

k) Indeksering en ekserpering

0000

l) Opstel van bibliografieë

0000

2 Spesifieke gebruikersgroepe soos:
a) Akademici
b) Kinders
c) Bejaardes en huisgebondenes
d) Sakelui
e) Vakspesialiste
f) Ongeletterdes
g) Gevangenes
h) Hospitaalpasiënte

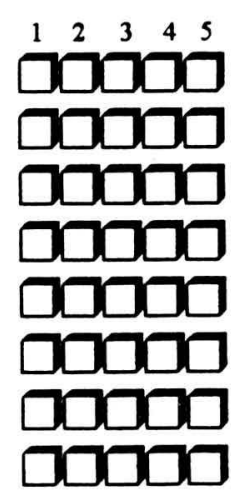

Kommentaar

B.9 Tot watter mate sal vroeë diversifikasie

a) ' $n$ Beperkende invloed op dienste hê?

$\check{1}_{\square}^{2}{ }^{3} \stackrel{4}{\square}^{5}$

b) Dienste voordelig beïnvloed?

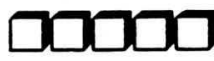

c) Werkgeleenthede beperk?

d) Aanstel / keuse van personeel vergemaklik?

0000

e) Vordering binne ' $n$ organisasie vergemaklik?

0000

00000

\section{Kommentaar}

\section{AFDELING C}

C.1 Hoe aanvaarbaar sal elk van die volgende toelatingsvereistes volgens u mening wees vir die tweede intree-/uittreevlak?

a) Senior sertifikaat (matriek)

b) St. 9 plus twee jaar ondervinding in ' $n$ biblioteek- en inligtingsdiens

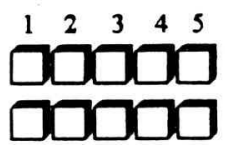


c) Ouderdom 23 jaar en ouer en die slaag van ' $n$ toelatingseksamen

d) Sertifikaat in biblioteek- en inligtingspraktyk $\square 0000$

\section{Kommentaar}

C.2 Tot watter mate sal ' $n$ kombinasie van ' $n$ voorgeskrewe aantal sertifikate as gelykwaardig aan 'n diploma aanvaar word?

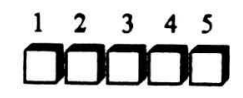

Kommentaar

C.3 Hoe belangrik is dit dat daar op hierdie vlak vryheid van keuse moet wees ten opsigte van voorkeur aan:

a) Biblioteektipe?

b) Spesifieke taak binne die biblioteek- en inligtingsdiens?

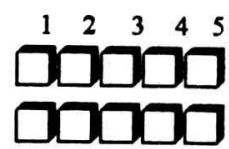

\section{Kommentaar}

C.4 Hoe belangrik is dit dat technikonstudente die geleentheid moet hê om toegang tot ' $n$ graadkursus te verkry?

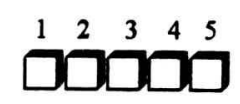

\section{Kommentaar}

C.5 Hoe aanvaarbaar sal elk van die volgende toelatingsvereistes volgens u mening wees vir die derde intree-/uittreevlak?

a) Senior sertifikaat (matriek)

b) St. 9 plus twee jaar ondervinding in 'n biblioteek- en inligtingsdiens

c) Ouderdom 23 jaar en ouer en die slaag van ' $n$ toelatingseksamen

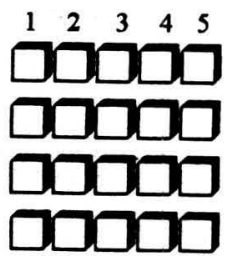

d) Nasionale Diploma: Biblioteek- en inligtingspraktyk

\section{Kommentaar}

